\title{
A carta de Galileu \\ à Grã-Duquesa Cristina de Lorena
}

Carlos Arthur Ribeiro do Nascimento*

Resumo: O propósito deste artigo é mostrar como a carta de Galileu a Cristina de Lorena procura compatibilizar o sistema copernicano com o texto bíblico. Para isso, ela obedece aos cânones da arte de escrever cartas (ars dictaminis) codificados desde a Idade Média, cujas partes tradicionais são: saudação, captatio benevolentiae, exposição, petição e conclusão. Palavras-chave: ars dictaminis - retórica - copernicanismo - ciência moderna - Galileu tradição jesuítica

Galileu, como outros autores do século XVII, tem um vasto epistolário que ocupa nove volumes das Opere. Edizione Nazionale (vols. 10-18), sem falar de outras cartas que foram inseridas em outros volumes.

Essas cartas tratam de questões variadas, desde problemas científicos até discussões estéticas. Um grupo de cartas muito citadas é constituído por aquelas que se referem especialmente à relação do sistema de Copérnico com a Sagrada Escritura. Trata-se especialmente de quatro cartas dirigidas a Benedetto Castelli (21/12/1613), a Piero Dini (16/2/1615 e 23/3/1615) e à

* Professor do Departamento de Filosofia do Instituto de Filosofia e Ciências Humanas da Universidade Estadual de Campinas - IFCH-Unicamp. 
grã-duquesa mãe de Toscana, Cristina de Lorena (meados de 1615)(1). Estas cartas, que discutem a compatibilidade do sistema copernicano com o texto bíblico, estão publicadas no Vol. 5 das Opere (Galilei 2, Vol. 5, p. 281-370); tiveram como motivação circunstancial uma discussão havida sobre este as. sunto durante um jantar na corte da Toscana em 12/12/1613. Intervieram na discussão Dom Benedetto Castelli, o professor de filosofia Cosimo Boscaglia e a própria grã-duquesa.

O núcleo do problema está no fato de que o sistema de Copérnico sustenta que o Sol está imóvel no centro de nosso sistema planetário, ao passo que a Terra, além de girar em torno de si mesma, descreve um órbita em torno do Sol. Ora, isto, pelo menos aparentemente, contradiz o texto da Bíblia, que afirma em várias lugares (Salmos 18, 6 e 103, 5; 1 Crônicas 16, 20; Eclesiastes 1, 4-6; Josué 10, 12 - o texto mais conhecido) a imobilidade da Terra e a mobilidade do Sol.

Para compatibilizar o sistema copernicano com o texto bíblico, Galileu recorre a uma estratégia básica constante. Em princípio, o conflito, para ele, só pode ser aparente, pois tanto a Natureza (Natura) como a Escritura (Scrittura) são obras de Deus. São mesmo os dois livros pelos quais Deus fala à humanidade (cf. Carta a Cristina de Lorena, id., ibid., Vol. 5, p. 317 e 329), e, portanto, imunes de erro. Quem pode errar são os intérpretes da Escritura, que não entenderiam adequadamente o que ela diz, ou os estudiosos da Natureza, que tomariam por demonstração rigorosa o que não passa de hipótese ou opinião. Posto isto, Galileu aponta na direção do que tem sido denominado "teoria da irrelevância" e "teoria da acomodação". Quer dizer, a Bíblia é um texto religioso e moral, e não um texto científico. Cita a este propósito o epigrama atribuído ao cardeal Barônio (1538-1607): "A intenção do Espírito Santo é ensinar-nos com se vai para o céu e não como vai o céu". Por outro lado, a Bíblia, para alcançar sua finalidade própria, usa de uma linguagem corrente em determinado contexto cultural. Ela se adapta ou se acomoda ao modo de falar costumeiro. Seria, pois, um despropósito pretender tomar seu texto, seja como um discurso científico e técnico, seja como devendo ser entendido sempre literalmente. 
Como Galileu considera que a Natureza está sujeita a regras de estrita necessidade e o discurso da Escritura não está adstrito a regras tão rigorosas, uma vez determinada a verdade científica, esta deverá servir de guia na interpretação da Escritura. Sua estratégia básica já está esboçada na carta a Castelli e encontra seu desenvolvimento pleno na carta a Cristina de Lorena. Basta considerar que a primeira ocupa apenas oito páginas da Edizione Nazionale e a segunda quarenta páginas, para perceber que Galileu desenvolveu muito mais sua argumentação nesta última e que se valeu desta carta quase como se fosse um pequeno tratado. De fato, este tipo de carta não tinha um destino unicamente individual, sendo endereçada unicamente ao destinatário aparente. A carta a Castelli circulava em Florença de mão em mão, como indica o frade dominicano Niccolò Lorini, que enviou uma cópia adulterada ao Santo Ofício em 7/2/1615. A carta a Cristina de Lorena só foi publicada em 1636, mas circulou bastante sob a forma manuscrita. Antonio Favaro, o organizador da Edizione Nazionale, examinou trinta e quatro manuscritos para preparar o texto publicado nesta edição (cf. Galilei 2, Vol. 5, p. 272-8).

A carta a Cristina de Lorena obedece aos cânones da arte de escrever cartas (ars dictaminis) codificados já na Idade Média. De acordo com a análise de Jean Dietz Moss ${ }^{(2)}$, é possível identificar as partes tradicionais de uma carta: saudação, captatio benevolentiae, exposição, petição e conclusão (Dietz Moss 1).

A saudação é respeitosa: "Galileu Galilei à Sereníssima Senhora, a Grã-Duquesa Mãe". Mas Galileu engata a primeira frase do texto projetando sua pessoa: "Eu descobri há poucos anos, como bem sabe Vossa Alteza Sereníssima, muitas particularidades no céu [...]" (Galilei 2, Vol. 5, p. 309).

A captatio benevolentiae apresenta as realizações de Galileu e os ataques injustos de seus rivais. O estilo é direto e lógico, revelando um estudioso fervoroso, dedicado e aguerrido. É um homem de boa vontade, que busca apenas a verdade; seus adversários nem sempre. As artimanhas destes são apresentadas na exposição (narratio). Segue-se uma parte que não é costumeira em cartas, isto é, a divisio e a refutatio. Quer dizer: 1) a identificação dos pontos particulares (argumentos) que seus adversários apresentam para 
banir o sistema de Copérnico, não só como falso mas também como heréti. co; 2) refutação destes argumentos - é aqui que aparecem os argumentos da acomodação e da irrelevância, apontados anteriormente.

A petição (petitio), à parte o que já foi inserido no decorrer da carta, consiste num apelo a favor de se fazer uso dos sentidos e do intelecto, dons de Deus à humanidade, e não pretender tapar a boca daqueles que os utilizam com um abuso das Escrituras.

Um trecho faz uma exegese concordista do milagre de Josué, procurando mostrar como ele se explica muito bem no sistema copernicano, o que não acontece no sistema ptolomaico (Galilei 2, Vol. 5, p. 344-7). Galileu era de certo modo obrigado a abordar esta questão, pois a grã-duquesa a ela se referiu na discussão durante o jantar de 12/12/1613. A carta se fecha com uma conclusão no mesmo tom desta explicação do milagre de Josué (id., ibid., p. 348).

Apesar do seu brilhantismo retórico, a carta não obteve o fim almejado: convencer as autoridades eclesiásticas de que não havia razão para condenar o sistema de Copérnico. Este foi censurado pelo Santo Ofício a 24/21 1616, e a obra de Copérnico - As revoluções dos orbes celestes - foi suspensa, até que fosse corrigida, por um decreto da Congregação do Índice de 5/3/1616.

Por que Galileu falhou? Pergunta complicada, longamente examinada por Jean Dietz Moss no artigo já mencionado. Indiquemos apenas a resposta global.

"Talvez a razão para isso repouse numa notória característica do argumento retórico: ele tende a convencer aqueles que desejam crer de qualquer modo em sua conclusão, ao passo que ele sobretudo irrita aqueles que acham tal conclusão inaceitável. Nos dias atuais, quando as pessoas em geral crêem que a Terra se move, alguém pode ficar inteiramente satisfeito e até mesmo encantado com a habilidade retórica de Galileu; em 1632, especialmente em Roma e Florença, quando o peso da autoridade e a evidência do senso comum estavam claramente contra esta conclusão, alguém poderia de 
modo igualmente fácil ficar irritado diante da petulância da tentativa de Galileu em forçar sua aceitação" (Wallace 6, p. 309) ${ }^{(3)}$.

A carta a Cristina de Lorena contém uma verdadeira ladainha que fala de "experiências sensíveis e demonstrações necessárias" em apoio do sistema de Copérnico. Mas Galileu, salvo uma alusão mais explícita, não as apresenta (cf. Galilei 2, Vol. 5, p. 328; Dietz Moss 1, p. 567 e 562-3). Ora, era o que o cardeal Bellarmino pedia...

Abstract: The aim of this article is to show how the Galileo's letter to Christina of Lorena seeks the compatibility between the Copernican system of world and the biblical text. For that, it obeys the canons of the art of writing letters (ars dictaminis) codified since the Middle Ages, whose traditional parts are: salutation, captatio benevolentiae, exposition, petition and conclusion.

Key-words: ars dictaminis - rethoric - Copernicanism - modern science - Galileo - Jesuitic tradition

\section{Notas}

(1) Estas cartas encontram-se traduzidas e reunidas em Galilei 4; a carta a Cristina de Lorena, também em Galilei 3.

(2) Ver especialmente as p. 551 e ss.

(3) Wallace está se referindo ao Diálogo sobre os dois máximos sistemas do mundo, donde a data de 1632, objeto do estudo de Finocchiaro. Mas a análise aplica-se também à carta a Cristina de Lorena, e Jean Dietz Moss indica sua dívida para com Finocchiaro. Para uma breve introdução ao Diá$\mathrm{log}_{0}$, cf. Nascimento 5 . 


\section{Referências Bibliográficas}

1. DIETZ MOSS, J. “Galileo's letter to Christina: some rhetorical considerations”. In: Renaissance Quarterly, Vol. 36, 1983, p. 547-76.

2. GALILEI, G. Opere. Edizione Nazionale [...]. 20 vols. em 21 tomos. Sob a direção de A. Favaro. Florença, Barbera, 1890-1909.

3.

"Carta a senhora Cristina de Lorena, grã-duquesa da Toscana". Trad. e intr. de C.A.R. do Nascimento. In: Cadernos de História e Filo. sofia da Ciência, Vol. 5, 1983, p. 91-123.

4. Ciência e fé. Cartas de Galileu sobre a questão religiosa. Intr. e trad. de C.A.R. do Nascimento. São Paulo/Rio de Janeiro, Nova Stellal Instituto Cultural Ítalo-Brasileiro, MAST, 1988.

5. NASCIMENTO, C.A.R. do. Para ler Galileu Galilei: Diálogos sobre os dois máximos sistemas do mundo. São Paulo, Nova Stella/Educ, 1990.

7. WALLACE, W.A. "Resenha do livro de M.A. Finocchiaro, Galileo and the art of reasoning: rhetorical foundations of logic and scientific method". In: Journal of the History of Philosophy, Vol. 20, 1982, p. 307-9. 